\title{
Industry 4.0: Reality, Future or just Science Fiction? How to Convince Today's Management to Invest in Tomorrow's Future! Successful Strategies for Industry 4.0 and Manufacturing IT
}

\author{
Stephan Gentner*
}

\begin{abstract}
Manufacturing IT and Industry 4.0 is the Fourth Industrial Revolution with a potential of 12 bn Euros in Germany's chemicals industry. But Switzerland is currently the best prepared of all countries in Europe. Many of the ideas are still very vague. This article discusses how to identify what is already reality, which ideas might become reality in the future and which ideas will stay science fiction. As projects in Manufacturing IT and Industry 4.0 are different from classical technical projects other strategies, for example agile project management, are necessary to secure success.
\end{abstract}

Keywords: Chemical production · Industry $4.0 \cdot$ Manufacturing IT

\section{Introduction}

Of all countries in Europe, Switzerland is currently the best prepared to deal with the challenges posed by Industry 4.0. But Germany has more potential: Industry 4.0 has the ability to create added value of $12 \mathrm{bn}$ Euros in Germany's chemicals industry over the next ten years.

Automation is considered to be the Third Industrial Revolution. Automation has simplified and changed our lives. It is no longer necessary for humans to perform tedious, repetitive activities, and this frees up workforces to apply their skills and training to more complex tasks instead (Fig. 1).

In the past few years, however, we have heard more and more about digitalization, manufacturing IT and Industry 4.0 - all hallmarks of what is being referred to as the Fourth Industrial Revolution.

There is no shortage of ideas or areas where action could be taken. But it's not always clear whether the ideas are realistic for the future or nothing more than a pipe dream. Key success factors in projects, particularly IT projects, which by their

${ }^{*}$ Correspondence: S. Gentner E-Mail: Stephan.Gentner@dsm.com DSM Nutritional Products $\mathrm{GmbH}$ Emil-Barell-Strasse 3

D-79639 Grenzach-Wyhlen

Germany nature are very abstract and less tangible and so hard to achieve are communication and clearly defined goals. This challenge can be successfully overcome by applying the principles of agile project management and making sure that success stories are available at an early stage to be used as a springboard for further actions. Success stories are an important way of getting en-

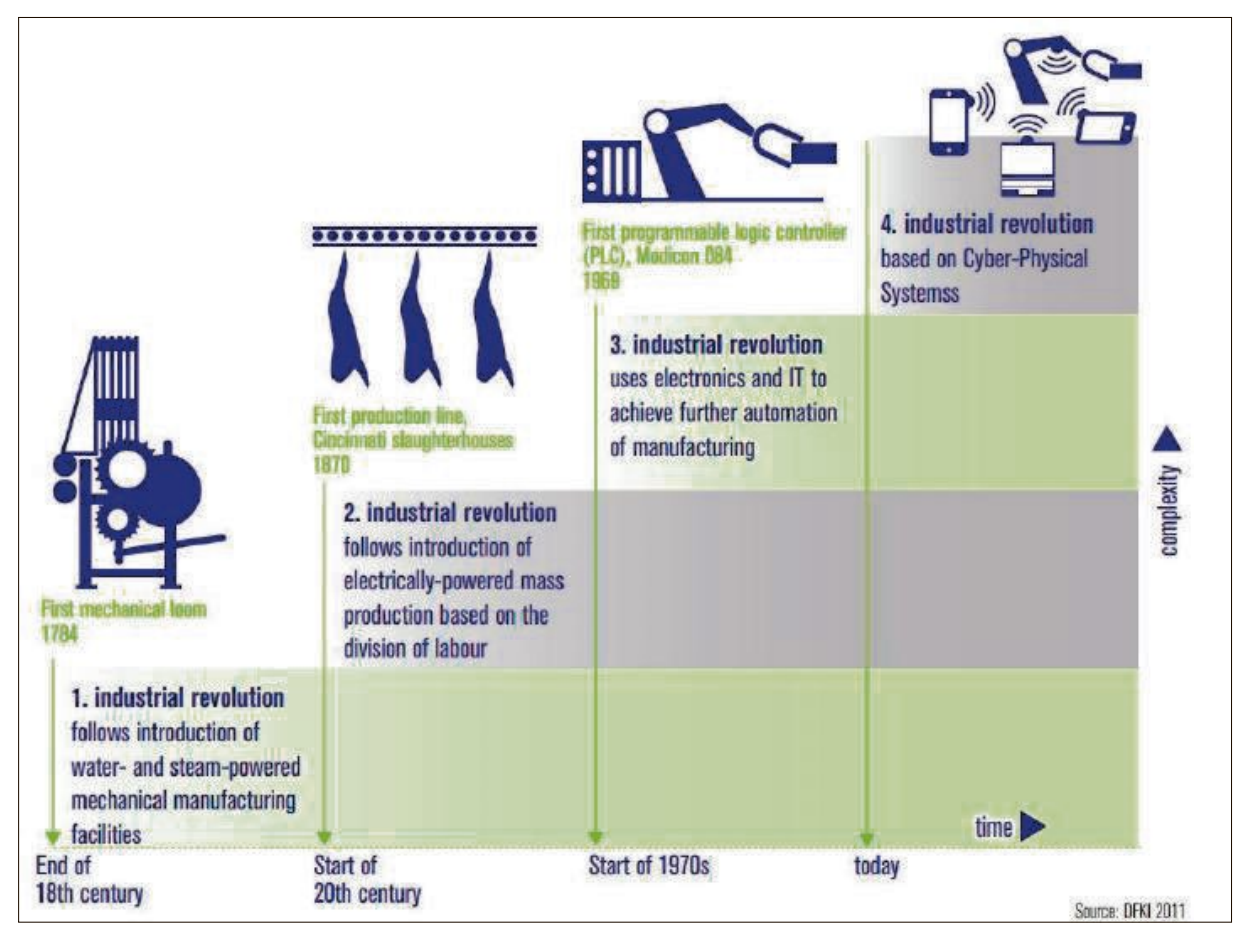

Fig. 1. The four stages of the industrial revolution. ${ }^{[1]}$ Reproduced with permission, Bitkom e.V., 2014 trepreneurs on board. Workshops defining the future state can help in the early stages to develop a clear vision and link it to your strategy. And repeatedly making your achievements visible helps, too.

Industry 4.0 will change our lives yet again. Many ideas will remain in the realm of science fiction, but others will become reality. Industry 4.0 can be seen as an op- 
portunity - but also as a threat: people are worried about job security. However, we must remember that since the invention of the steam engine people have always found jobs, despite the rise of automation. Steam engines and motors supplemented or replaced human muscle power. In parallel, we can see Industry 4.0 as enhancing our brain power. This is a fundamentally different technology, and its impact will be much broader. In order to exploit the benefits of this technology, we need to channel it in a way that creates prosperity for all. And in doing so, it is crucial to get everyone on board and support them in making this journey.

\section{Tomorrow's Future or Today's Reality?}

Is this Industry 4.0 only a vision of the future or is it already today's reality? And what does this mean for our daily work?

\section{Digital Workplace}

Publications are no longer written on a computer but spoken into a microphone and then converted into written text by voice recognition software. Indeed, the author has used Dragon $®$ voice recognition software for the composition of this article.

What if suppliers would no longer send paper invoices? Instead, they submit electronic invoices as PDF files. These are scanned using character and image recognition software, compared with the original order and, if all data match, automatically paid. At no point does an employee need to check the invoice. At DSM Nutritional Products Ltd., this became reality several months ago!

\section{Digital Manufacturing, Planning and Supply Chain}

A chemical production process has been automated to the extent that a human operator is no longer needed. There is no longer a control room. If a problem arises, the system automatically switches to a loop mode and starts up on its own once the problem has been resolved. An employee receives a text message and can operate the facility from home using a tablet device.

Since the early nineties this is already reality in a production plant at BASF Kaisten (Switzerland). DSM Nutritional Products Ltd. (Switzerland) is investing in its wastewater treatment plant to move in this direction. This will entail the implementation of 48 individual measures. Cameras will also be installed to detect safety-related accidents. This technology is reliably available today.

At BAYER Grenzach (Germany), customer orders are used to control production by automatically adjusting the production scale up or down. It is no longer necessary to have a production planner. The forklifts are unmanned and are steered by induction loops in the floor.

In Hamburg's container terminal, driverless, fully automated container transport vehicles have recently been introduced.

The manager of a manufacturing company stands alone in front of an interactive video screen. The supercomputer is called Celia. A hurricane is forming. The manager asks Celia which plants will be most severely affected. In mere seconds, Celia analyzes the current weather reports and ranks the plants according to the probability of incurring damage. Celia then suggests measures, the manager selects one and Celia sends out job orders. A team of several people would have needed days to complete the same task. The Celia supercomputer is made by IBM. IBM is currently working on a pilot project with the Repsol oil and gas company. It is conceivable that in ten years, event notification services and emergency organisations will operate very differently than they do today.[2]

IBM's Watson computer is a HAZOP black belt (hazard and operability study): Watson recognizes words, images, P\&ID items, requirement specifications and workplace regulations. The computer assesses risks and potential damages. Employees must only define the necessary measures to prevent damage. The reinsurer Swiss Re uses Watson to estimate risks and assess damages. It is conceivable that HAZOPS will be conducted in a completely different way in ten years. ${ }^{[2]}$

\section{Digital Maintenance}

A repairman begins his workday by looking at the requests for repairs on his tablet. The software has already sorted the jobs according to priority. First, the worker repairs a pump, takes photographs of the damage with the explosion-proof tablet, describes the nature of the damage and the measures taken to repair it, and records the hours spent on the job. All of this is done on the tablet. The software is synchronized with SAP R/3. In the oil industry, this scenario is already reality. At DSM Nutritional Products Ltd. (Switzerland), the necessary explosion-proof WLAN networks have been installed recently.

\section{Reality, Future or just Science Fiction?}

Computers are capable of learning today. Once the computer becomes good enough at a task, it takes on $80 \%$ of the workload. For instance, Google Translate was fed multilingual texts and then taught itself to translate. The translation output is fully adequate to understand most texts. Only difficult texts are given to human translators. ${ }^{[2]}$
In California's Silicon Valley robots perform police duties - and successfully so. Patrolling streets is dull and tedious, which is why the turnover rate at security companies is so high. The 'robocops' do not replace police officers but assist them. They can detect suspicious odors and behavior and trigger an alarm. Police can then use their skills and training to perform more demanding tasks.

It has been shown that the time required for shift changes can be reduced from 20 minutes to 5 minutes when the control overviews are given a more user-friendly structure. An alarm management system will help systematically reduce the number of alarms in the plant. Interfaces between the electronic shift book and SAP R/3 are introduced at DSM Nutritional Products Ltd., so that the operator error messages no longer have to be recorded twice in two systems.

These many examples show that industry is already striding towards Industry 4.0 today. Our future depends on how we use technology and how we bring people along on the journey within the next few years. We have it in our own hands to shape our future.

\section{Successful Strategies for Industry 4.0 and Manufacturing IT}

The Global Competitiveness Report 2015-2016 of the World Economic Forum assesses the competitiveness landscape of 140 economies, providing insight into the drivers of their productivity and prosperity (Fig. 2). ${ }^{[3]}$ Switzerland tops the Global Competitive Index, ahead of Singapore, the USA and Germany. It is in second place in the 'technological readiness' cluster after Luxembourg. Of all countries in Europe, Switzerland is currently the best prepared to deal with the challenges posed by Industry 4.0 and Manufacturing IT, although Germany has more potential.

\section{Potential and Readiness}

Industry 4.0 has the potential to create added value of 12 bn euros in Germany's chemicals industry over the next ten years. [1]

Swiss companies now just have to capitalize on their excellent starting position and potential for added value. What does it take to make a success of investing in a future that is far from clear.

\section{Success Factors}

Manufacturing IT and Industry 4.0 projects are full of traps for the unwary. These need to be identified to avoid the risk of failure. 'Manufacturing IT' stands for 'Information Technology in Manufacturing', which is usually IT 


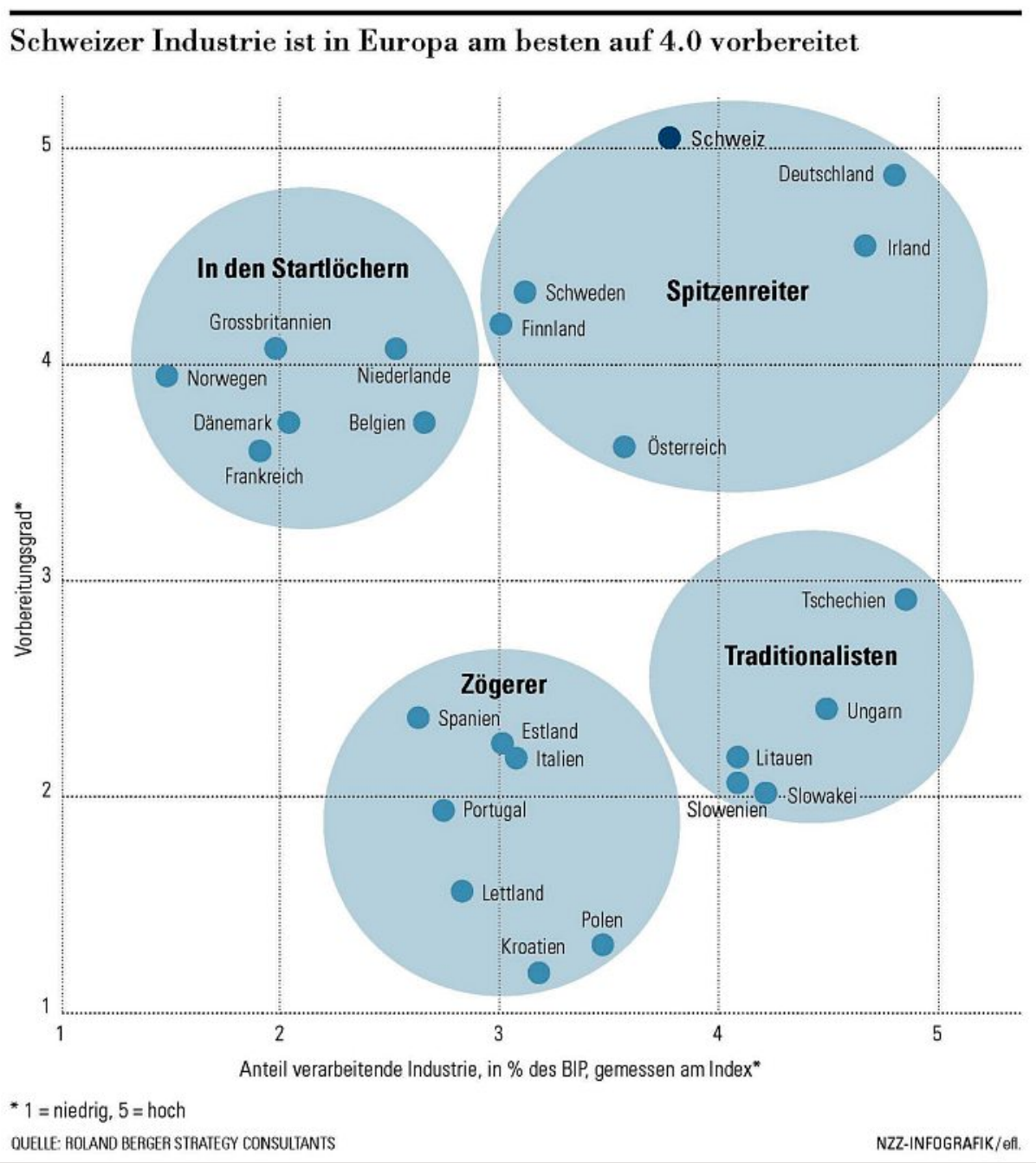

Fig. 2. Of all countries in Europe, Switzerland is currently the best prepared to deal with the challenges, although Germany has more potential. ${ }^{[1]}$ Reproduced with permission, Bitkom e.V., 2014

projects. Studies of the Standish Group Massachusetts ${ }^{[4]}$ show that $80 \%$ of all IT projects fail. This is a shocking figure: simply speaking it means that failure is normal. Success is the exception rather than the rule. $50 \%$ of projects overspend AND miss their deadlines, whilst $30 \%$ of projects finish without any results. Manufacturing projects in the construction industry, for example, are far more successful. So the first question to be answered is what the success factors for projects are and why they seem to be so difficult to achieve in IT projects.

Studies have shown that the top two success factors in projects are good communication and goal definition. Other success factors such as keeping deadlines, well defined structure of work packages, project staff expertise and project financial controls are often overrated.

Communication and defining goals are usually no problem in manufacturing projects because the entrepreneur and the project manager speak the same language. The entrepreneur says he wants to build a new packaging line in order to expand and the project manager proposes various op-
They operate in a far more abstract and intangible world. The project manager is concerned about technical details, which the entrepreneur does not understand and cannot relate to. As a consequence he loses confidence in the project and is dissatisfied with the realized efficiency gain that are usually expected by IT projects. He can't make the business case for investing in the project. The project manager is annoyed because he is now left with an image of an athletics competition in his head. Communication in IT projects is demanding, as well as defining goals. In IT projects and in particular in Industry 4.0 we are at the start of a development process and often have no idea what the solution might ultimately look like. That's difficult to communicate.

Agile project management, taking one small step at a time, starting small to take bigger steps later, has proven useful here. It is important to work to standards and with major partners. One advantage of this approach is the quick generation of success stories, which don't need to be huge. It's enough to use a few examples as a way of communicating and defining the goal. These small success stories should be used to repeatedly discuss with all stakeholders what the project is about (communication) and to set the direction of travel (defining goals). The goals may change with every new success story. This is a new and more flexible approach compared to manufacturing projects and needs a shift in attitudes. However, it is essential given the rapid pace of development in this area. Just one year ago it wasn't possible to use cameras as part of a security system to detect catastrophic failures and trigger alarms. Today it is. So it's important for the project managers and entrepreneurs to stay agile and have the capacity to deal with a certain amount of uncertainty.

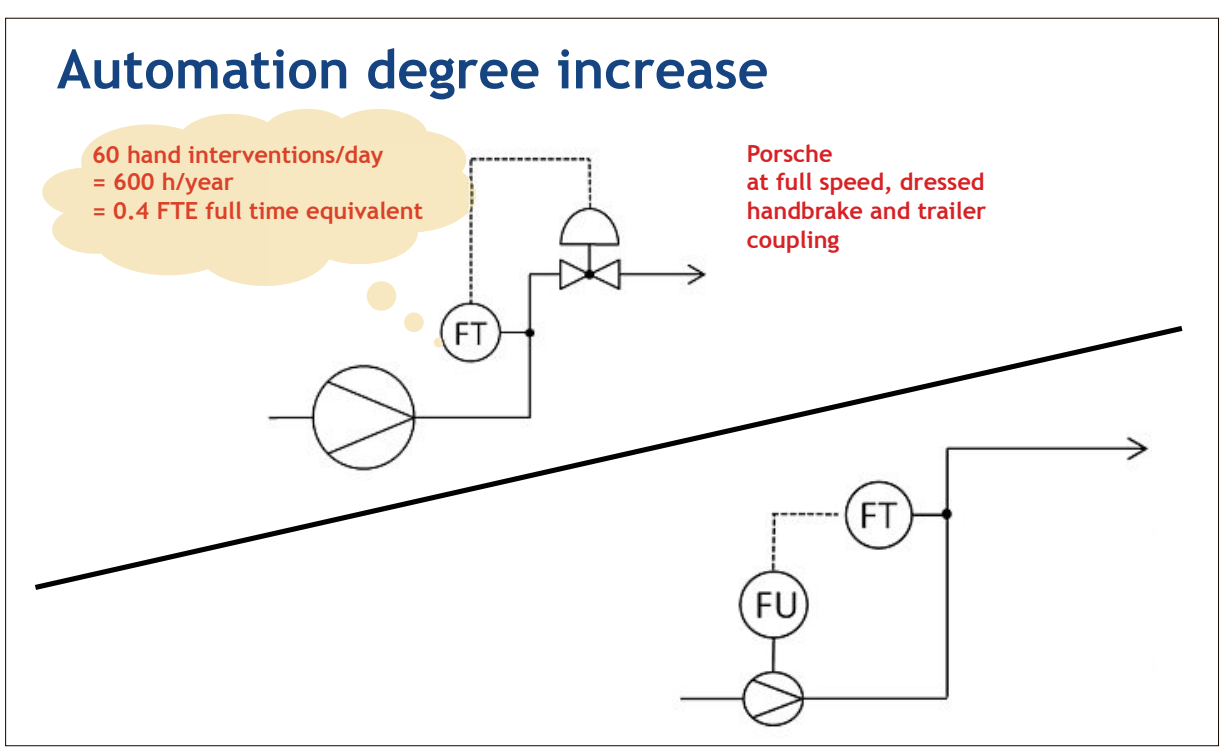

Fig. 3. Communication of success story example between project manager and entrepreneur. 


\section{Storytelling and Success Stories}

In a recent example an analytical tool was used to analyze the alarms in a highly-automated chemicals production plant (alarm management system). Thereby one area of the plant could be identified where the operator carried out small manual feed corrections every few minutes.

The analysis showed that the highly corrosive and abrasive chemicals at this location have slowly but steadily destroyed the control valve over a six-month period. The operator made manual adjustments to compensate for the control error this caused. This continued up to the point where the entire valve had to be replaced, but the manual interventions then simply resumed, of course. The solution to the problem was striking in its simplicity (Fig. 3). The control valve was removed and a frequency transformer fitted to the pump to regulate the feed. The sole task of a frequency transformer is to turn the pump speed down when less feed is required and up when more feed is needed. As this simplifies the design of the pump considerably, abrasion was no longer a problem at this location. Today, the solution itself is very simple in technical terms. But this was not the case just 10 years ago, when it was not possible to buy reliable frequency transformers permitted for use in explosive atmospheres.

This example made investing in an alarm management tool palatable for the entrepreneur. It also helped to build trust and to illustrate plausibly and visually what Manufacturing IT can do. In order to make the case more tangible a simple comparison was used. Using a control valve to regulate a feed will always mean that the pump is too large and consuming more energy, as it always has to be capable of supplying the largest possible feed. The pump is running full speed with a manual valve to regulate the feed. This is comparable to driving a Porsche flat out at full speed but then having to slam on the handbrake and coupling a trailer too. Another analogy is central heating circulation pumps. These often don't have flow speed regulators installed. Today we know that we could take several nuclear power plants off the grid if we replaced all these pumps. However this is rarely done because electricity is too cheap to make a convincing business case. These sorts of examples and small success stories are key to obtain the necessary investments.

Alarm management and this specific example could open the door for taking further steps. One next step was to automate entire plants. At the current state of the art it is perfectly possible to automate individual unit operations such as rectification or extraction. But in most cases the operator continues to run the plant manual-

\section{Example for top down Approach: 'stand alone' process units}
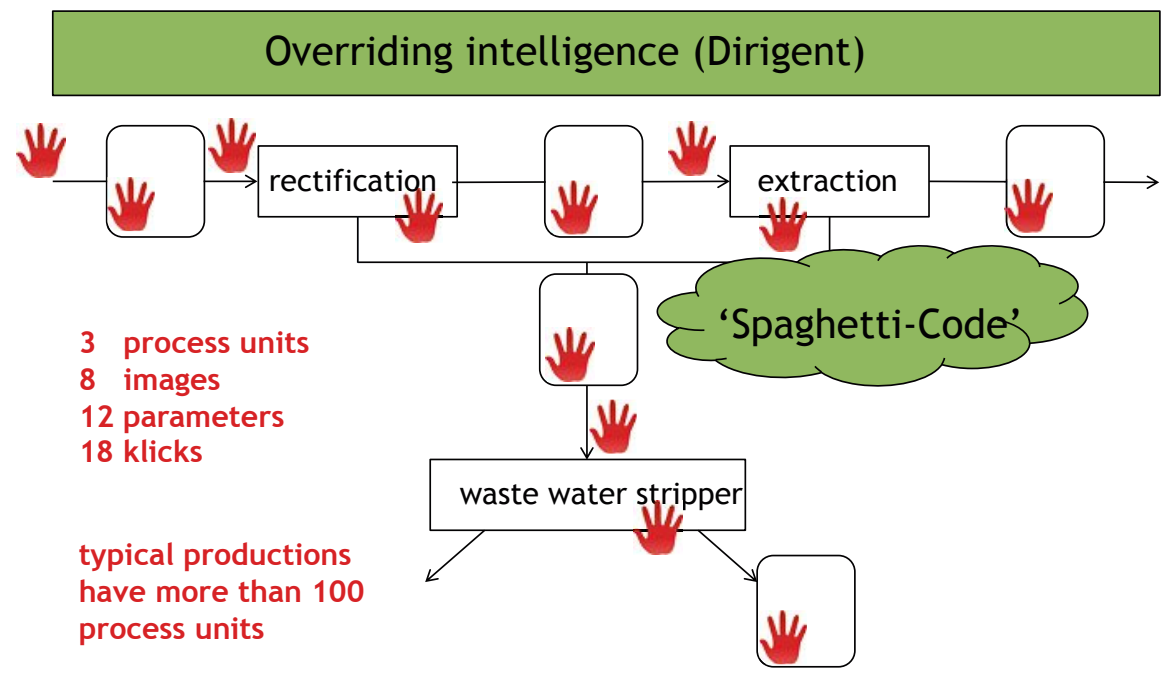

Fig. 4. Manual interventions in an automated plant. ly. So he issues a manual command to start rectification and then a command to start extraction based on the levels in the intermediate tanks. When the plant is running the operator then has to keep checking and adjusting the levels, feeds and plant status. With three unit operations the information required is spread across nine images. To control the twelve parameters he has to make a total of 18 mouse clicks and when he has checked everything he starts over again (Fig. 4). This is not a value-creating activity. One would expect major companies to have a solution for this. But many don't. In the chemicals industry and particularly in the pharmaceuticals industry with its high margins and relatively small batch processes, there was no need for this in the past.

One option for resolving this dilemma and increasing automation is 'spaghetti code', which uses 'if-then' logic in the program code. That works well when the plant is operating. But if a blockage occurs in the plant, the operator can no longer run the plant because he cannot see how the individual unit operations relate to each other (Fig. 5). An overriding control system would help. This would act like a conductor, orchestrating the individual unit operations and tank systems. Since this is not (yet) available, one workaround is to

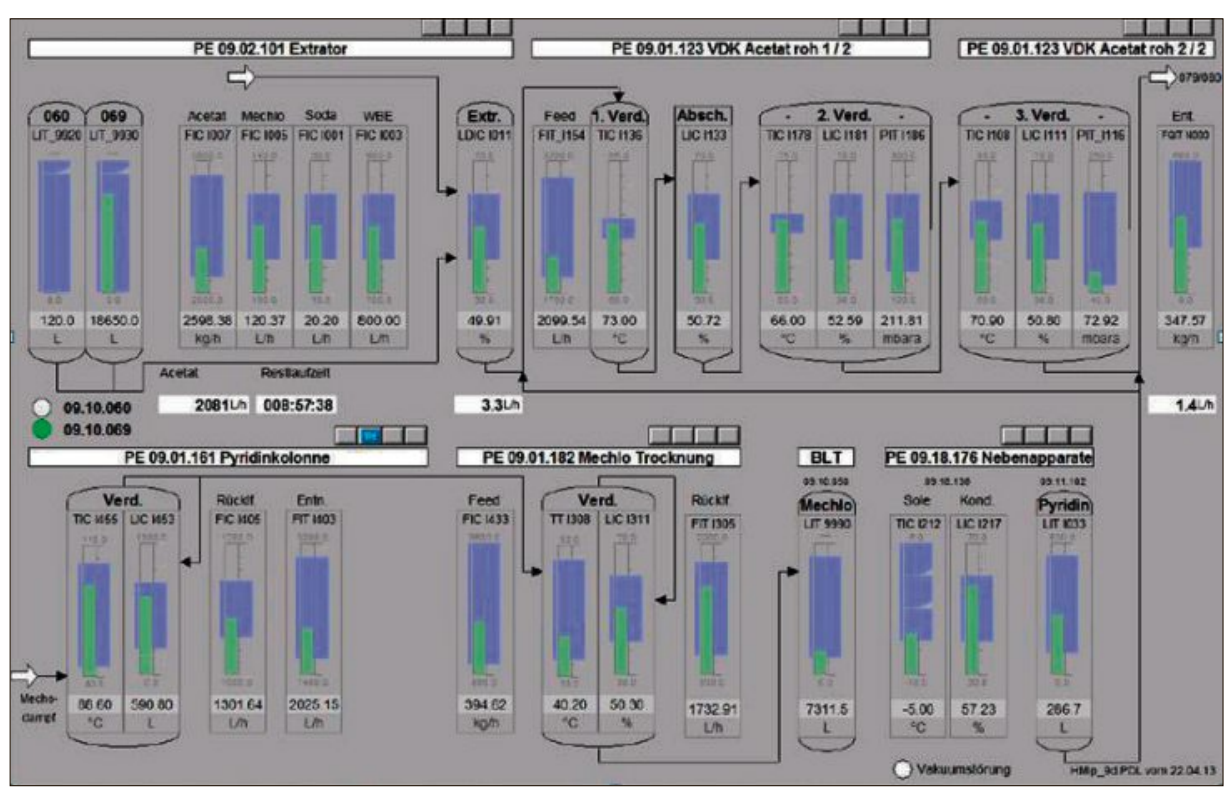

Fig. 5. Conventional displays. 
optimize the displays for the operator so he no longer needs 18 clicks but can see all the relevant information on a single screen.

Using displays optimized in this way has shown that handover between shifts can be reduced from 20 minutes to 5 minutes (Fig. 6). This means that overtime can be significantly reduced.

\section{Approach}

These are additional examples that help to advance the Manufacturing IT and Industry 4.0 process. Starting small means it's no big deal if you fail. Losses are small, but confidence in the project and in Industry 4.0 is retained. Starting small may mean for example that alarm management and job analyses can be used as metaphorical door openers, which can then serve as a base on which to take the next, larger steps such as introducing an EBR Electronic Batch Record Systems or robots (Fig. 7).

\section{Vision}

Every company needs to start out by considering what its vision is and what strategy will bring about success most rapidly. Conducting a future state workshop with all stakeholders where you think about what the plant should look like in five years has proven to be helpful in developing a vision. This step is extremely important. Without a vision you might be left stuck at the display stage (Figs 5 and $6)$. But if you generate a vision of developing for example, a driverless airport metro system, the optimized displays are only an intermediate step on a path that is yet to be travelled. Without vision, all you can do is solve problems, but you remain average. Excellence requires a vision.

\section{Strategy}

In this dynamic environment of Industry 4.0 it is hard to develop a strategy, as it may very well be that something will

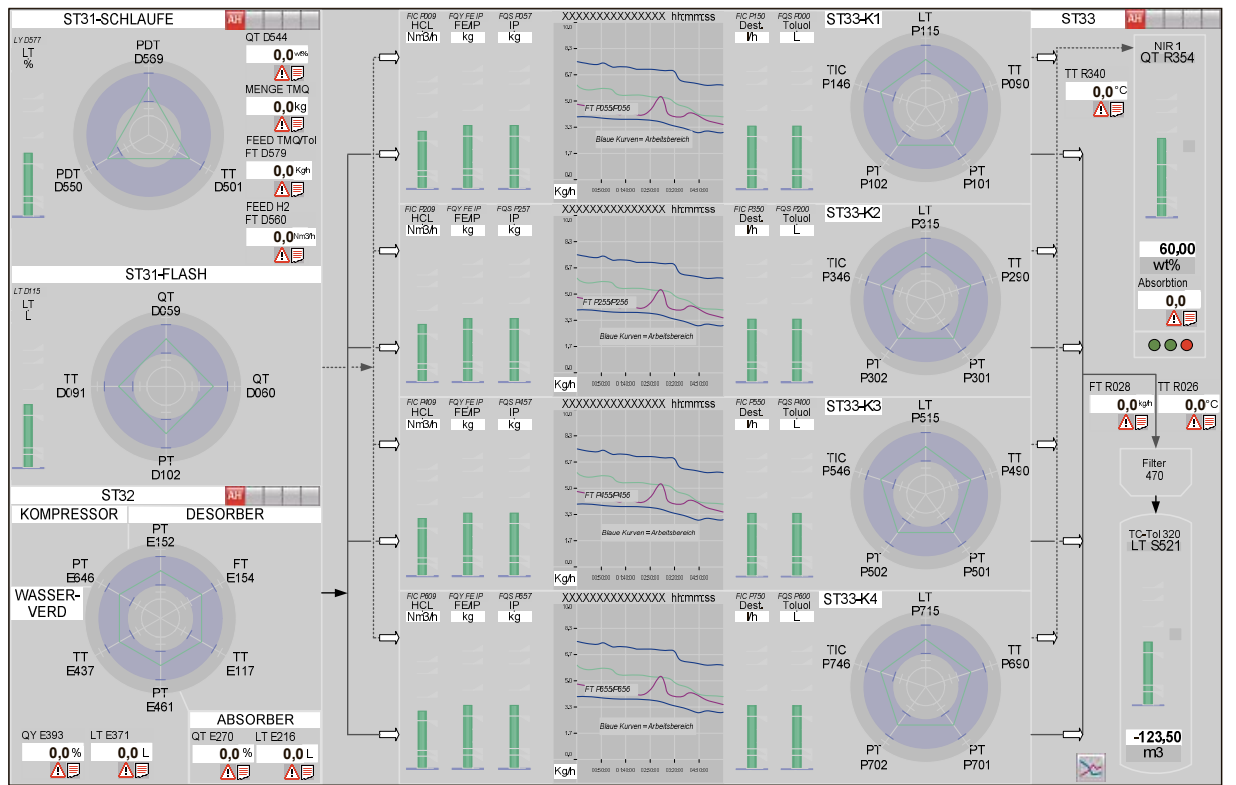

Fig. 6. Displays with spider charts.

Approach

\section{Start small and get bigger (with standards and big partners)}

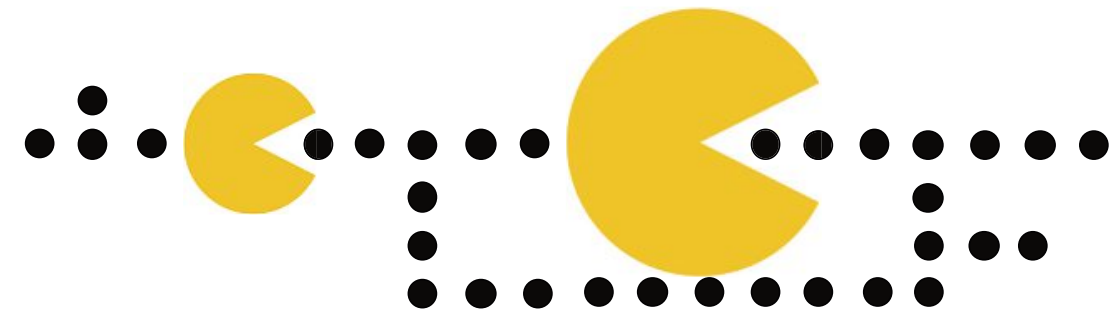

work tomorrow but is not technically feasible yet. And also because we ourselves are constantly shaping and thus changing the future. But the entrepreneur needs a strategy because it provides him with the security that the project is well managed. A list showing the areas to work on to get closer to the vision has proven to be a useful tool (Fig. 8). But then agility is required to take a flexible approach to this list. If a component is not successful it is removed from the list and no more work is done on it. It may be replaced by another area entirely. With agile project management that is not a problem but an opportunity, but the key consideration always has to be whether this is the right course of action to achieve success.

\section{Tracking Success}

Making success visible is key. One way of doing this is to record and assign a value to every idea in working hours (Fig. 9). Industry 4.0 and Manufacturing IT projects typically reduce workload. This ultimately allows person hours to be reduced or released for more value-creating activities (Fig. 10).

Our future depends on how we use technology and how we bring people along on the journey. And we're not talking about tomorrow but about the next few years. We ourselves are in the position to shape our own future.

Of all countries in Europe, Switzerland is the best prepared to deal with the challenges posed by Industry 4.0. With agile project management, a company vision for Manufacturing IT and Industry 4.0, a strategy and small but consistent steps, you can successfully overcome the challenges of IT projects whilst at the same time bringing employees and company management along on the journey.

Received: July 14, 2016

\begin{tabular}{|l|l|}
\hline 1 & Alarmmanagement \\
\hline 2 & Working analysis \\
\hline 3 & Increase automation level \\
\hline 4 & $\mathrm{HMI}+$ Human machine interface \\
\hline 5 & Statistical process control \\
\hline 6 & Asset management \\
\hline 7 & OEE Tool \\
\hline 8 & Golden Batch \\
\hline 9 & Lot protocols/LIMS connection \\
\hline 10 & Online operational management \\
\hline 11 & Production planning \\
\hline
\end{tabular}

Fig. 8. Example of a strategy.

Fig. 7. Process: the PacMan represents success and increases in size with each sub-step. 


\begin{tabular}{|c|c|c|c|c|c|c|c|}
\hline Tătigkeit & Verlust & $\begin{array}{r}\text { Anzahl } \\
\text { pro Jahr } \\
\end{array}$ & $\begin{array}{c}\text { Verlust- } \\
\text { grösse } \\
\end{array}$ & $\begin{array}{c}\text { Verlust } \\
\text { bei } 46 \\
\text { Prod.Wo/ } \\
\text { Jahr } \\
\end{array}$ & $\begin{array}{c}100 \mathrm{CHF} / \\
\text { Std. }\end{array}$ & Massnahme & Invest \\
\hline & & & \begin{tabular}{|l} 
Minuten/ \\
Tätigkeit
\end{tabular} & \begin{tabular}{|c|} 
Stunden/ \\
Jahr
\end{tabular} & CHF/Jahr & & \\
\hline $\begin{array}{l}\text { Umstellung von der Feed von Fundabac- } \\
\text { Filter } 22.06 .515 \text { auf Fundabac-Filter } \\
22.06 .517 \text { und umgekehrt. Findet alle } 48 \\
\text { Stunde statt. }\end{array}$ & \begin{tabular}{|l|} 
Bedienereingriffe/Alarme \\
350TCL22/01365/GF013401/W_FEED \\
350TCL22/06517/SFC06517//RUN \\
350TCL22/06515/SFC06515//RUN \\
350TCL22/01365/GF013401/02/FIC_B \\
350TCL22/01365/GF013401/05/FV_B4
\end{tabular} & 10000 & 1 & 167 & 16667 & Neuer Ablauf der PE's & 17000 \\
\hline
\end{tabular}

Fig. 9. Ideas list.

\section{Manufacturing IT = Workload reduction}

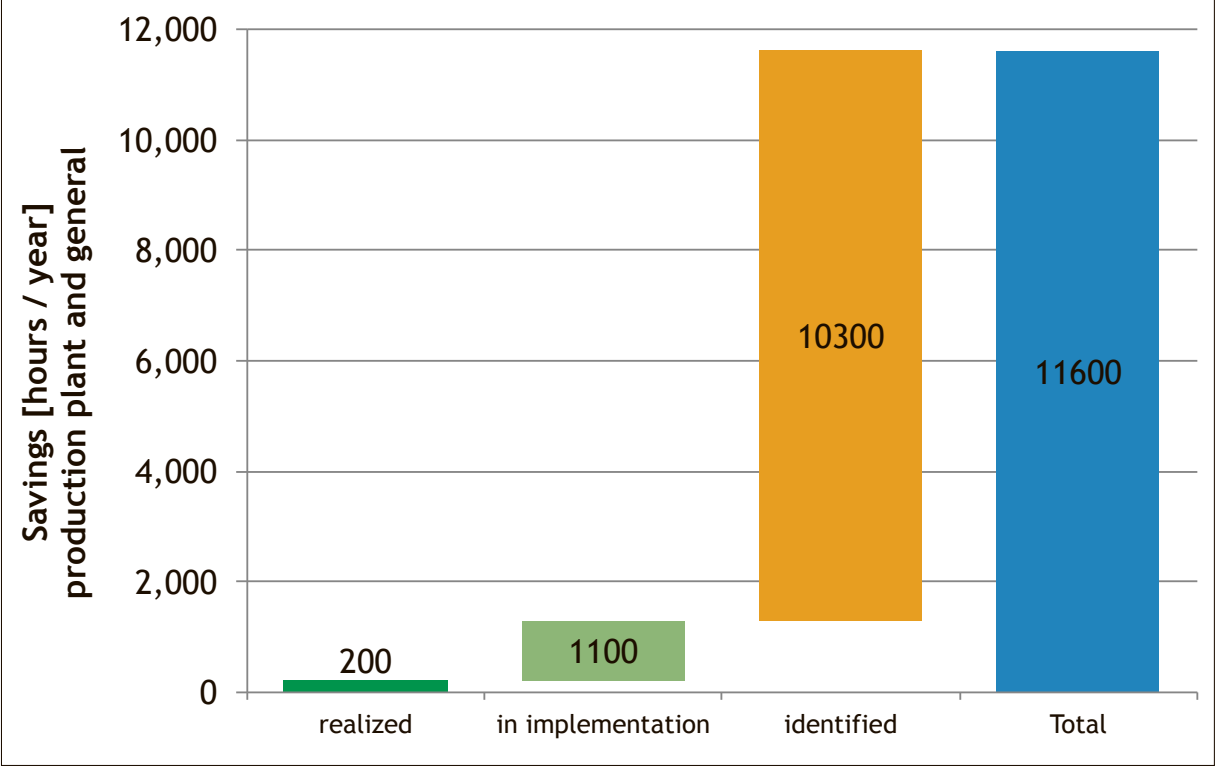

Fig. 10. Visualizing success.
[1] 'Industrie 4.0 - Volkswirtschaftliches Potenzial für Deutschland', Studie BITKOM BerlinMitte, Fraunhofer-Institut Stuttgart, 2014, DOI: https://www.researchgate.net/figure/ 284719780_fig1_Figure-1-The-four-stages-ofthe-Industrial-Revolution-2 [accessed Jul 19, 2016]

[2] M. Metzler, NZZ am Sonntag, 03.01.2016.

[3] 'Global Competitiveness Report 2015-2016 of the World Economic Forum', Ed. K. Schwab, 2015, 336, DOI: http://www3.weforum.org/ docs/gcr/2015-2016/Global_Competitiveness Report_2015-2016.pdf

[4] K. Pfetzing, A. Rohde, Ganzheitliches Projektmanagement 2009, 48 . 